\title{
The Expert Medical Witness
}

\author{
Patrick C. Doran MD CORR 1956;8:254-258
}

M edicolegal issues have long been important to society and the medical and legal professions, as suggested by this month's Classic, "Report of the Committee on Suits for Malpractice" [6] by Eugene F. Sanger and an earlier report by the same author [5]. (Google Scholar lists 92 entries antedating 1800.) We highlight this month an article, "The Expert Medical Witness" by Dr. Patrick Doran published in 1956 [3]. A few years later, in 1964 under the guest editorship of Drs. Earl McBride and William Deyerle, CORR published its first of several symposia on medicolegal issues (readers may refer to Volumes 32, 406, and 433) as is this month's symposium.

A key part of medicolegal proceedings is the expert witness. Sanger [6] expressed concerns about expert witnesses over 100 years ago, including those who were inadequately trained, those who provide testimony only to support an otherwise unjustified suit just for pay, and those who would disappear after testimony so they could not again be contacted. Doran noted three types of witnesses in the State of Ohio [3]: (1) a witness of fact, (2) a professional medical witness, and (3) a medical expert witness. A doctor can, of course, be asked (or subpoenaed) to serve as a witness of fact as can any other citizen: doctors observe many events that can be subject to subsequent litigation or criminal proceedings. A professional medical witness could be called to describe the facts of a case, including a description of care, disability, expenses, etc., but need not be an expert. An expert medical witness, on the other hand, had added qualifications and experience to address matters of compensation or (I suspect) testimony of standard of care.

Doran [3] conducted a small and informal survey of "judges, industrial commission referees, adjusters, trial lawyers (both reputed plaintiff and defending types), court reporters and jurors." He asked four questions:

Question 1. Do doctors (orthopaedists) impress you as wholly honest and sincere in their court testimony and in the medicolegal relations?

Question 2. What is your reaction when diametrically opposed testimony is offered by opposing experts (plaintiff's expert versus defendant's expert)?

Question 3. What qualities and/or characteristics of the experts are most effective?

Question 4. Could you suggest any improvements?

Based on the answers, Doran concluded the response to medical witnesses was generally favorable. However, the industrial commission referees were "...the least impressed by the doctor's integrity. At times, the fantastic connections made by testimony regarding the aggravating factors and the causes of some wellknown disease of spontaneous onset probably were responsible for their derogatory attitude" [3].

The American Academy of Orthopaedic Surgeons introduced in 2004 an Expert Witness Program [1] designed to maintain "the high ethical standards contained in the AAOS Code of Medical Ethics and Professionalism and the Advisory Statement on Orthopaedic Medical Testimony." Clearly, ethical standards have evolved since the time of Sanger [5] and Doran [3]. Interested readers should review current standards of the AAOS in the Expert Witness program and associated documents [2, 4].

Richard A. Brand MD Editor-in-Chief Clinical Orthopaedics and Related Research

\section{References}

1. AAOS Expert Witness Program. Available at: http://www3.aaos.org/member/ expwit/expertwitness.cfm. Accessed December 3, 2008.

2. Code of Ethics and Professionalism for Orthopaedic Surgeons. Available at: http://www.aaos.org/about/papers/ ethics/code.asp. Accessed December 3, 2008 . 


\section{Years Ago in CORR}

3. Doran PC. The expert medical
witness. Clin Orthop Relat Res. 1956; 8:254-258.

4. Expert Witness Affirmation Statement. Available at: http://www3. aaos.org/member/expwit/statement.cfm. Accessed December 3, 2008.
5. Sanger EF. A Report on Malpractice to the Maine Medical Association. Portland, ME: Stephen Berry, Printer; 1878.

6. Sanger EF. Report of the Committee on Suits for Malpractice. Trans Maine Med Assoc. 1879;6:1-22.
50 Years Ago in CORR:

The Expert Medical Witness Patrick C. Doran MD

Richard A. Brand MD 